\title{
Chromosome analysis in polyploid human embryos
}

\author{
H.W.Michelmann, A.Bonhoff' ${ }^{1}$ and L.Mettler \\ Department of Obstetrics and Gynaecology, University of Kiel, \\ Hegewischstr. 4, D-2300 Kiel 1, FRG \\ 'Present address: F.Hoffmann-La Roche, Basel, Switzerland
}

Cytogenetic investigations have been performed on 436 unfertilized or polyploid human oocytes after in-vitro fertilization at the Department of Obstetrics and Gynaecology, University of Kiel. Thirty-two oocytes had more than two pronuclei 16-20 $\mathrm{h}$ after fertilization and were therefore potentially the precursors of polyploid embryos. The total number of fertilized oocytes was 667 , and the frequency of tripronucleate ova was $4.8 \%$. These tripronucleate eggs may develop normally up to birth but never lead to viable newborn children. Some of the resulting embryos displayed chromosomal mosaicism, where polyploid karyotypes and normal diploid cells occurred together. It is assumed that the survival rate of polyploid embryos depends upon the percentage of normal diploid cells.

\section{Introduction}

Despite the fact that until $1985>2300$ children have been born after in-vitro fertilization (IVF) and embryo transfer (ET) it is clear that only $20-25 \%$ of all replacements lead to a pregnancy. Various reasons might be responsible for this low rate of success. One of them could be a non-diploid chromosome complement in some embryos.

The incidence of genomic variations (euploidy) is independent of the genotype of the parental germ cells. In most cases, polyspermic fertilization is the cause of polyploidy. After in-vivo fertilization, an estimated rate of $75 \%$ of all conceptions are lost, most of them unnoticed. Triploidy was detected in $18.9 \%$ of all abortions investigated after narural conception (Lauritsen, 1982), and Hassold et al. (1980) found the same incidence of polyploidy in 1120 aborted embryos (15.1\%). After in-vivo fertilization, $1.8 \%$ of all fertilized oocytes are thought to be polyploid. By performing IVF this rate increases up to $10 \%$, and the question arises about the responsible factors.

The use of hormonal stimulation during IVF was expected to be one reason for polyspermic reactions. But Gray and Chrisman (1980) could not find any connection between stimulation and the rate of polyploidy during IVF in the mouse. However, Maudlin and Fraser (1977) and Dankowski et al. (1981) established a correlation between the intensity of hormonal stimulation and the incidence of polyploidy in laboratory animals.

The identification of chromosomally-aberrant embryos proved to be rather difficult, because polyploid mouse embryos do not necessarily show any signs of morphological degeneration (McLaren, 1976). They can be viable for a certain time period. Similar observations were made in man, for polyploid embryos do not necessarily die during the pre-implantation stage. Steptoe et al. (1980) reported the first genome mutation after human IVF when a triploid embryo was aborted in the 12th week of pregnan- cy. The only way to prevent pregnancies carrying polyploid embryos after IVF is by controlling fertilization $16-20 \mathrm{~h}$ after insemination. Oocytes with more than two pronuclei are considered to be polyploid. Trounson et al. (1982) found eight oocytes $(9.4 \%)$ out of 85 with more than two pronuclei. Rudak (1983) reported an incidence of $8.7 \%$ in 127 fertilized oocytes. According to Semm et al. (1985), the incidence after IVF in German clinics is $4.9 \%$ ( 372 oocytes out of 7649 ).

\section{Materials and methods}

Chromosomal analysis of human oocytes were performed after IVF only if no cleavage of the oocytes had occurred or in cases where fertilization had led to eggs with more than two pronuclei. This rather selected material was subjected to chromosomal studies.

The fertilization of a human oocyte occurs during meiosis II. Unfertilized eggs remain at metaphase II. At this stage, polar body chromosomes are clearly visi-

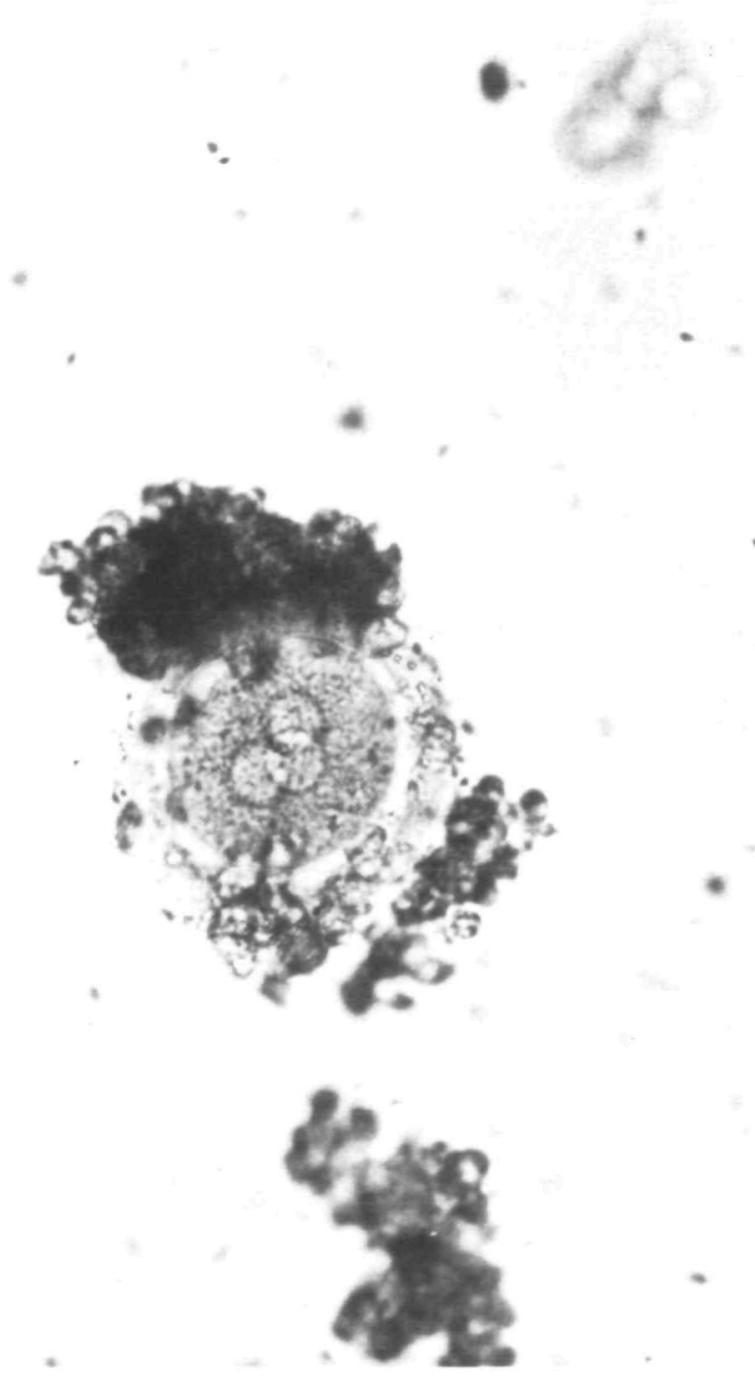

Fig. 1. Fertilized oocyte with three pronuclei. 


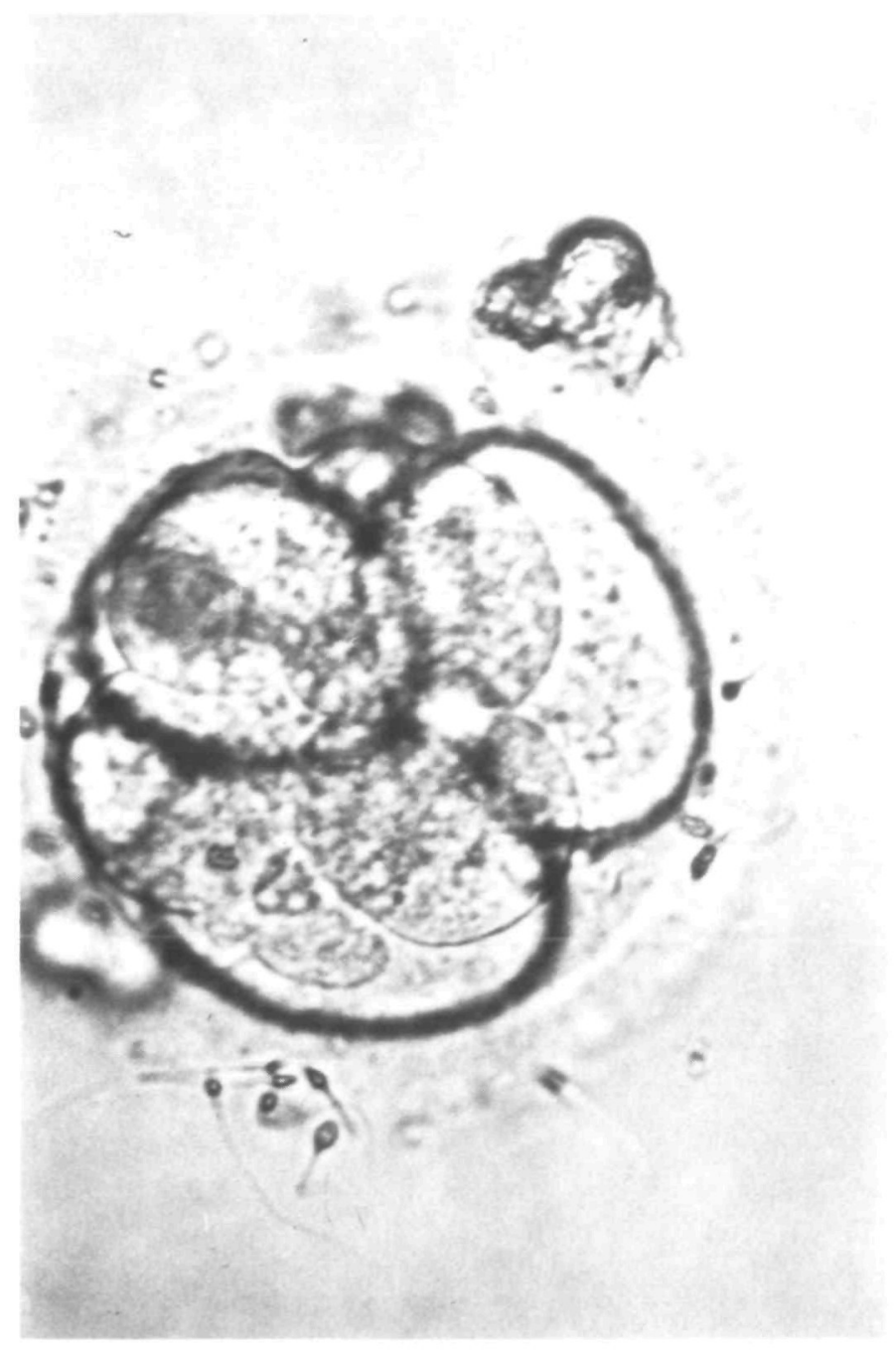

Fig. 2. Four- to eight-cell stage of a polyploid embryo.

ble. If oocytes were still uncleaved $44 \mathrm{~h}$ after insemination, they were considered unfertilized and free for cytogenetic analysis.

Presumed polyploid embryos have three or more pronuclei which can be observed by microscopy 16-20 h after fertilization. These embryos were cultured to different stages of embryonic development and analysed cytogenetically (Figures 1 and 2).

The techniques described by Tarkowski (1966) and King et al. (1979) were used to produce well-spread chromosomes from oocytes and early embryos.

Cytogenetic investigations were performed at the Department of Gynaecology in Kiel on a total of 436 human oocytes or early embryos.

\section{Results}

Cytogenetic investigations were performed on 436 unfertilized ocytes or on embryos developing from eggs with more than two pronuclei. In 185 cases $(42.4 \%)$, the analysis was successful.

From September 1983 until November 1985, 32 out of 667 fertilized oocytes $(4.8 \%)$ had more than two pronuclei. Twentyfive oocytes contained three pronuclei, five contained four pronuclei and two contained five pronuclei.

Polyploidy was confirmed in oocytes with more than two pronuclei. Microscopic analyses of these zygotes or early embryos provided no evidence of morphological aberrations. Details of the chromosomal analyses on 17 of the embryos are given in Table I.

Chromosomes could not be counted accurately in six embryos. Five embryos were triploid, two identifiable mitoses being found
Tabte I. Chromosome analysis of cleaving human embryos arising from fertilized eggs with more than two pronuclei

\begin{tabular}{rllllll}
\hline No. & $\begin{array}{l}\text { No. of } \\
\text { pronuclei }\end{array}$ & $\begin{array}{l}\text { No. of } \\
\text { cells in } \\
\text { the embryo }\end{array}$ & \multicolumn{4}{l}{$\begin{array}{l}\text { Chromosome analysis of } \\
\text { different blastomeres }\end{array}$} \\
\hline 1 & 3 & 1 & 2 & 3 & 4 \\
\hline 2 & 3 & 2 & $3 n$ & $?$ & & \\
3 & 3 & 2 & $3 n$ & $?$ & & \\
4 & 3 & 4 & $2 n$ & $1 n$ & $?$ & $?$ \\
5 & 3 & 4 & 02 & & & \\
6 & 3 & 4 & $2 n$ & $?$ & $?$ & $?$ \\
7 & 3 & 4 & $2 n$ & $2 n$ & $2 n$ & $?$ \\
8 & 3 & 4 & $3 n$ & $3 n$ & $?$ & $?$ \\
9 & 3 & 4 & $3 n$ & $3 n$ & $?$ & $?$ \\
10 & 3 & 4 & 0 & & & \\
11 & 3 & 4 & 0 & & & \\
12 & 3 & 4 & $3 n$ & $?$ & $?$ & $?$ \\
13 & 3 & 6 & 0 & & & \\
14 & 3 & 8 & 0 & & $?$ & $?$ \\
15 & 3 & 8 & $1 n$ & $?$ & $?$ & $?$ \\
16 & 3 & 8 & 0 & & & $?$ \\
17 & 4 & 8 & $2 n$ & $?$ & $?$ & $?$ \\
\hline
\end{tabular}

$20=$ no analysis possible.

in two of them, and a single mitosis in the others (Figure 3). One embryo was an extreme polyploid, of $7 n$. Two embryos were diploid/haploid mosaics. One of these had arisen from a fertilized egg with four pronuclei. The two remaining embryos had diploid mitoses only (Figure 4), one having three such mitoses. It was not possible to decide if these were uniform diploid or $\mathrm{diploid} /$ haploid mosaics, although three diploid mitoses without any haploids indicates that this embryo had reverted to diploid by the loss of one pronucleus at syngamy.

\section{Discussion}

The question arises as to whether polyploidy will occur to a greater extent in an IVF programme than after normal conception. According to investigatons of Trounson et al. (1982) and Rudak (1983), $9 \%$ of all fertilized eggs exhibit these aberrations. Compared with in-vivo fertilization with its estimated incidence of $1.5 \%$ of polyploid embryos, there seems to be a definite increase in aberrations. This may depend on the lack of a selection barrier to spermatozoa during fertilization in vitro, as the natural 'zona-block' is overcome by multiple penetration. On the other hand, the advanced age of the parents has to be considered. In Germany $>70 \%$ of all female IVF patients are above the age of $30 ; 21.5 \%$ above 35 . The frequency of chormosomallyaberrant offspring is known to increase after in-vivo fertilization with the advancing age of the mother.

In our own investigations on 667 fertilized eggs, $4.8 \%$ had more than two pronuclei, with an equal distribution through all age groups.

Polyploid embyros mainly arise after polyspermy. Many are able to pass normally through pre-implantation development, and our observations confirm that triploid embryos may develop up to the 8-cell stage. They do not exhibit any apparent morphological changes. At the time of embryo replacement (48 h post-insemination) they cannot be differentiated from normal embryos.

Some of the embryos under investigation were evidently triploid, and others showed cell mosaicism. Haploid and diploid karyotypes were identified in some embryos. We assume that 


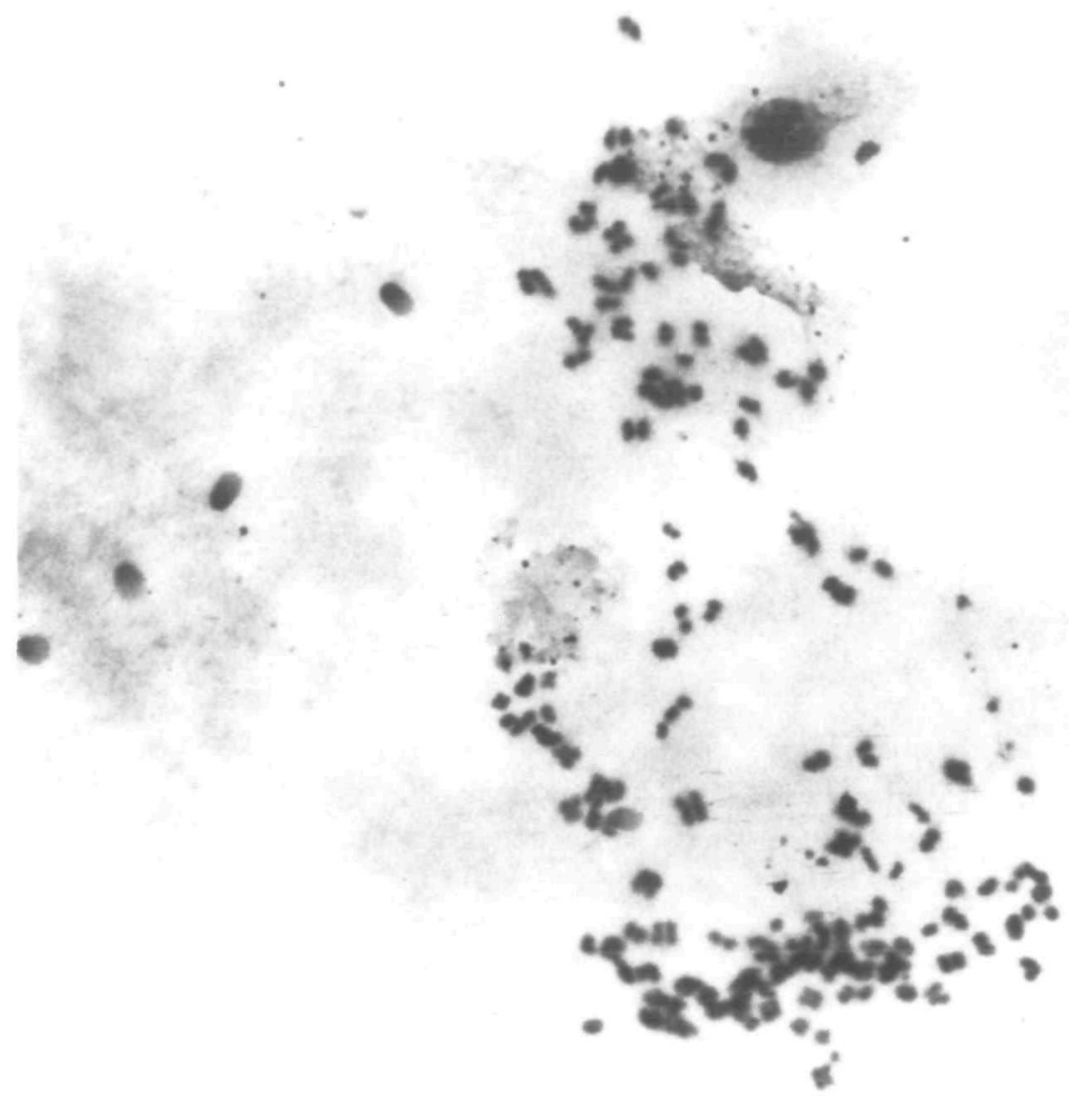

Fig. 3. Polyploid metaphase in a 2-cell embryo.

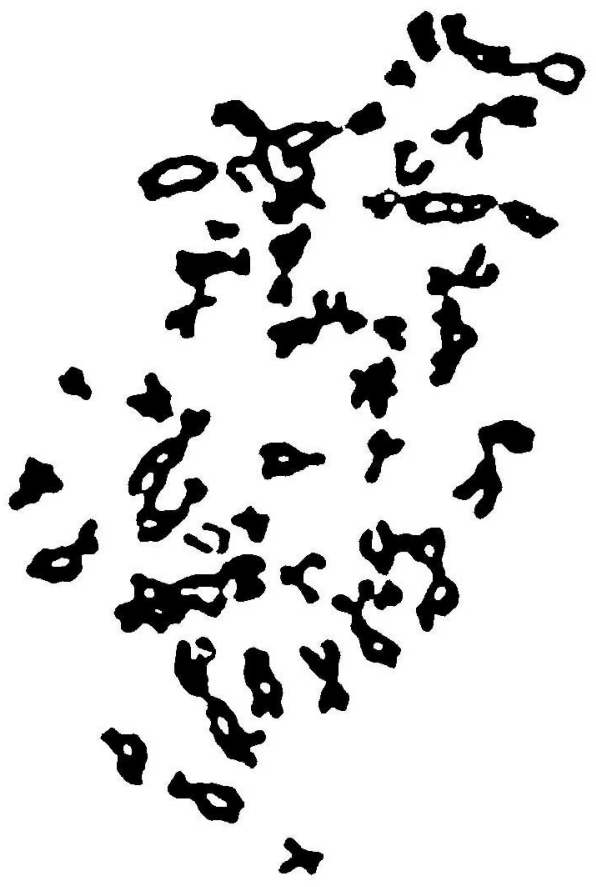

Fig. 4. Diploid metaphase in an embryo arising from a tripronucleate egg. 
tripronucleate or tetrapronucleate eggs lost some pronuclei at syngamy, or that one or more escaped syngamy, to establish a haploid cell line. The alternative explanation, that triploid cells divided cells during mitosis at an early embryo stage appears to be unlikely. The survival capacity of a polyploid embryo may depend upon its percentage of normal diploid cells. One embryo was highly polyploid.

It is difficult to detect the exact mechanisms causing embryonic mortality. A systematic evaluation can be performed if various factors are screened according to the time of their occurrence. Such time intervals include the process of fertilization as well as the pre- and post-implantation developmental stages. Using IVF techniques with embryo culture, we are able to observe the developmental stages of an embryo and can attempt to identify lethal factors. These can be gene-, chromosome- or genome mutations, endogenous (immunological or endocrine) as well as exogenous influences, the latter being dependent on nutrition, climate, trauma, toxicity or infection. The careful screening of embryonic mortality in vivo and in vitro will help to improve the replacement rates after IVF as well as to aid in establishing the reasons for early embryonic death.

\section{References}

Dankowski,K., Schneider,K. and Hahn,J. (1981) Zytogenetische Untersuchungen an Mäusecizellen nach Superovulation. Zuchthygiene, 16, 85-89.

Gray,M.H. and Chrisman,C.L. (1980) The effect of pregnant mare serum gonadotropin on mouse oocytes as monitored at metaphase II. Theriogenology, 13, $165-170$

Hassold,T., Chen,J., Funkhoaser, J., Jooss, T., Mannel,B., Matsuura,J., Matsuyama,A., Wilson,C., Yamane,J.A. and Jacobs,P.A. (1980) A cytogenetic study of 1000 spontancous abortions. Ann. Hum. Genet., 44, 151- 178.

King, W.A., Linares, T., Gustavsson,J. and Bane, A. (1979) A method for preparation of chromosomes from bovine zygotes and blastocysts. Vet. Sci. Commun., $3,51-56$.

Lauritsen,J.G. (1982) The cytogenetics of spontaneous abortion. Res. Reprod., 14, $3-4$.

Maudlin,I. and Fraser,L.R. (1977) The effect of PMSG dose on the incidence of chromsomal anomalies in mouse embryos fertilized in virro. J. Reprad. Feriil., 50, 275-280.

McLaren, A. (1976) A genetics of the early mouse embryo. Arnu. Rev. Genet., 10, $361-388$.

Rudak,E., Dor,J., Mashiach,S., Nebel,L. and Goldmann, B. (1983) Human embryo chromosomes. In Feichtinger, W. and Kemeter,P. (eds), Recent Progress in Human in Vitro Fertilization. Cofese Edizioni, Palermo, Italy, 231 pp.

Semm,K., Michelmann,H.W. and Mettler,L. (1985) Derzeitiger Stand der Invitro-Fertilisation (extrakorporale Befruchtung beim Menschen). Gynaekol. Geburtshil., 4, 27-37.

Steptoe,P.C., Edwards,R. and Purdy,J.M. (1980) Clinical aspects of pregnancies established with cleaving embryos grown in virro. Br. J. Obstet. Gynaecol., 87, $757-768$.

Tarkowski,A.K. (1966) An air-drying method for chromosome preparations from mouse eggs. Cytogenetics, 5, 394-400.

Trounson,A.D., Mohr,L.R., Wood,C. and Leeton,J.F. (1982) In vitro ferilization, culture and transfer of human embryos: effect of delayed insemination. J. Reprod. Fertil., 64, 285.

Received on 5 April 1986; accepted on 14 April 1986 